\title{
An Exceptional Cause of Acute Appendicitis: Intrauterine Device
}

\author{
Ibrahim Aliosmanoglu ${ }^{\mathrm{a}, \mathrm{b}}$, Mesut Gul ${ }^{\mathrm{a}}$, Murat Kapan ${ }^{\mathrm{a}}$, Akin Onder ${ }^{\mathrm{a}}$, \\ Abdullah Boyuk ${ }^{\mathrm{a}}$, Metehan Gumus ${ }^{\mathrm{a}}$
}

\begin{abstract}
Appendiceal cases are quite common among surgical operations; however, intrauterine device (IUD) appendicitis is relatively rare in the literature. The aim of this study is to emphasize the possibility of IUD to develop as a reason for acute abdomen just like gynecological problems. A 35-year-old woman was admitted to our hospital due to abdominal pain and was detected with foreign body along with a clinical presentation of appendicitis on abdominal ultrasonography and an intrauterine device in post-appendectomy lumen. It should be noted that the women that are diagnosed with acute appendicitis are likely to develop IUD.
\end{abstract}

Keywords: Appendicitis; Foreign body; Intrauterine device

\section{Introduction}

Acute appendicitis is the most commonly detected reason for acute abdomen and it is evident in $1 \%$ of all surgical procedures [1]. Acute appendicitis arising from foreign body is quite rare, with a rate of $0.005 \%$ among appendectomy specimens [2]. Common foreign bodies include pyrenes and metal needles. However, a literature review spanning the past years only revealed a few reported cases. We report a case of a 35-year-old woman who was diagnosed with acute

Manuscript accepted for publication December 12, 2011

${ }^{a}$ Department of General Surgery, Medical Faculty, Dicle University, Diyarbakir, Turkey

${ }^{\mathrm{b}}$ Corresponding author: Ibrahim Aliosmanoglu, Dicle University Medical Faculty, Department of General Surgery, Seyrantepe mevkii, 21280, Diyarbakýr, Turkey. Email: ialiosman@gmail.com

doi: $10.4021 / \mathrm{jcs} 8 \mathrm{w}$ appendicitis and thus received appendectomy and who presented with intrauterine contraceptive device (IUD) in the appendectomy material, in an attempt to support the notion that IUD, just like gynecological problems, may also be a reason for acute abdomen.

\section{Case Report}

The 35-year-old woman was admitted to the department of Gynecology and Obstetrics due to abdominal pain. The patient had been using IUD for ten years and she had presented no problem regarding IUD during her regular check the year before; however, upon the detection of IUD migration via physical examination and pelvic ultrasonography (Usg), she was admitted to our department for further diagnosis and treatment. The patient stated that she had been suffering from infrequent abdominal pain for the last three months and that the pain had got more severe over the last three or four days as accompanied by nausea and vomiting. On physical

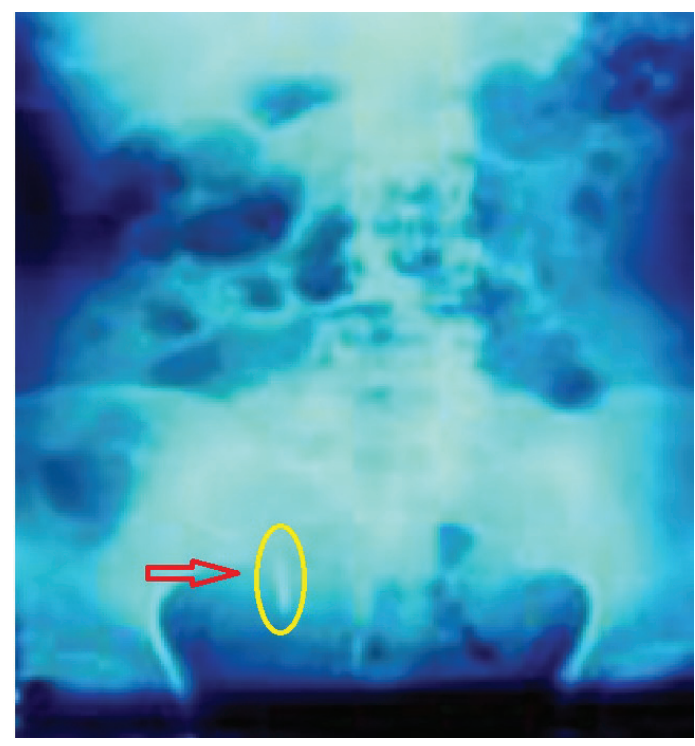

Figure 1. Pelvic X-ray film showing an intrauterine device in the lower right quadrant. 


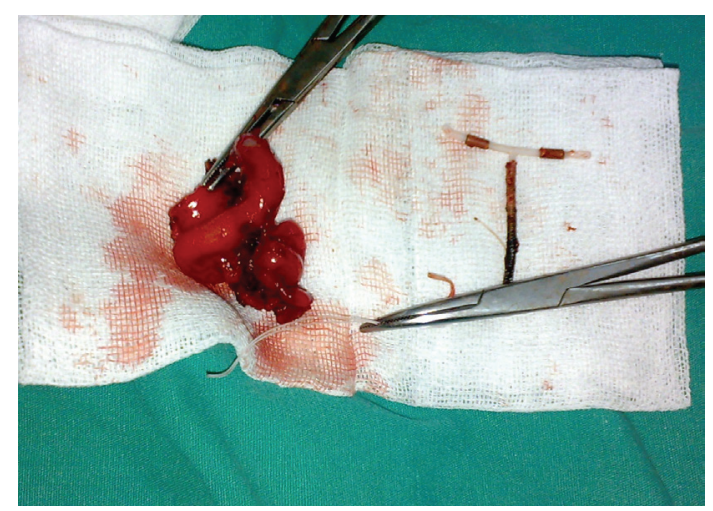

Figure 2. Intraoperative photograph showing IUD in appendiceal lumen.

examination, the abdomen was distended with tenderness, defense, and rebound in the lower right quadrant. Laboratory data were normal with an exception of white cell count of $13,500 / \mathrm{mm}^{3}$. IUD was visualized in the lower right quadrant on plain X-ray (Fig. 1). An abdominal X-ray confirmed the impressions of acute appendicitis and of foreign body in appendiceal lumen. Also, abdominal Usg confirmed minimal free fluid in the pelvis. The patient received laparotomy upon the diagnosis of acute appendicitis. The inflammation of the appendix was visualized at laparotomy. Dissection of the dense adhesions revealed a solid foreign body in the lumen of the appendix. Appendectomy was performed thereafter. The foreign body was confirmed as the intact body of IUD (Fig. 2). Also, it was noted that the body of the IUD had passed transversely through the lumen of the appendix and remained embedded in it. Further, the strings were spanning towards abdomen through the cecal lumen. Once the strings were removed, primary closure was performed for the caecum. The patient had an uneventful recovery and was discharged 5 days after operation. Acute appendicitis was confirmed histopathologically.

\section{Discussion}

Appendicitis is the most common reason for acute abdomen. Other reasons include fecal impaction, tumor, and, rarely, indigestible foreign bodies [2]. The rate of appendicitis arising from foreign bodies is reported as 5:100,000 while the number of asymptomatic foreign bodies detected in appendix is considered relatively higher $[2,3]$. The foreign bodies that cause acute appendicitis or appendiceal abscess are radiopaque and they are generally thin, sharp, solid, and long metal items. They are also reported to promote complications like intraabdominal abscess, fecal peritonitis, adhesions, fistula, and lead poisoning [2]. Collins et al detected fecalith with foreign body in $3 \%$ of 71,000 appendiceal cases [4]. Balch and Silver confirmed it in only 7 of the
13,228 cases that received appendectomy in 1971 [5]. In the order of frequency, common foreign bodies include metal needles, bones, pyrenes, stones, walnuts, coins, nails, teeth, metal keys, eggshells, toothpicks, chewing gums, dental inlays, animal feathers, fragments of thermometer, bristles of toothbrush, and plastic materials [6]. IUD is generally a safe modality for long-term contraception. Accompanying complications include bleeding, infection, ectopic pregnancy and uterine perforation. Uterine perforation is one of the most serious yet uncommon complications associated with IUD. The mechanism of perforation is considered to include insertion procedure or chronic inflammatory reaction with gradual erosion through the uterine wall [7]. For the present case, we considered that the mechanism of IUD perforation was secondary to the gradual erosion that might have occurred in the last 8 years prior to the present admission, and that the IUD had passed towards appendiceal lumen by penetrating the ileocecal junction. No fecalith impaction in the appendix was found during the operation, which made us consider that the acute appendicitis the result of chronic inflammatory reaction of the copper-containing IUD. Hao-Ming Chang et al reported a 50-year-old patient who had IUD penetration at the tip of the appendix [8]. A similar case was reported by F. Cuillier, in which the penetration was reported at the appendiceal lumen in a 42-year-old patient [9].

Plain X-ray and USG are crucial elements in the diagnosis of such cases. Radiopaque bodies are easily detected by plain radiograph. USG is useful in evaluating intraabdominal pathologies like acute appendicitis. For the cases with relevant symptoms, appendectomy is advised. For the asymptomatic foreign bodies that are coincidentally detected in the appendix or lower right quadrant via plain X-ray or USG, prophylactic laparoscopy or open surgery with appendectomy is suggested [2].

\section{Conclusion}

Acute appendicitis in women is likely to be mistaken with gynecological pathologies. It should be noted that the women that are diagnosed with acute appendicitis are likely to develop IUD and relevant complications during the pathological analyses in differential diagnosis.

\section{References}

1. Lewis FR, Holcroft JW, Boey J, Dunphy E. Appendicitis. A critical review of diagnosis and treatment in 1,000 cases. Arch Surg. 1975;110(5):677-684.

2. Klingler PJ, Seelig MH, DeVault KR, Wetscher GJ, Floch NR, Branton SA, Hinder RA. Ingested foreign bodies within the appendix: A 100-year review of the literature. Dig Dis. 1998;16(5):308-314.

3. Ekingen G, Guvenc BH, Senel U, Korkmaz M. Fluoros- 
copy-guided laparoscopy in the management of intraabdominal foreign body. J Pediatr Surg. 2003;38(9):E1920.

4. Collins DC. 71,000 Human Appendix Specimens. A Final Report, Summarizing Forty Years' Study. Am J Proctol. 1963;14:265-281.

5. Balch CM, Silver D. Foreign bodies in the appendix. Report of eight cases and review of the literature. Arch Surg. 1971;102(1):14-20.

6. Sukhotnik I, Klin B, Siplovich L. Foreign-body appendicitis. J Pediatr Surg. 1995;30(10):1515-1516.
7. Zakin D, Stern WZ, Rosenblatt R. Complete and partial uterine perforation and embedding following insertion of intrauterine devices. I. Classification, complications, mechanism, incidence, and missing string. Obstet Gynecol Surv. 1981;36(7):335-353.

8. Chang HM, Chen TW, Hsieh CB, Chen CJ, Yu JC, Liu YC, Shen KL, et al. Intrauterine contraceptive device appendicitis: a case report. World J Gastroenterol. 2005;11(34):5414-5415.

9. Cuillier F. IUCD appendicitis. Eur J Obstet Gynecol Reprod Biol. 2003;110(1):102-104. 